\title{
Five Year Survival Outcomes of Prospectively Recorded Cohort Data for Older Adults versus Younger Adults with Resected Primary Rectal Cancer
}

\author{
Mohsen Shafiei ${ }^{1,2}$, Philip Beale ${ }^{1,2}$, Prunella Blinman ${ }^{1,2}$ \\ ${ }^{1}$ Faculty of Medicine and Health, University of Sydney, Sydney, Australia \\ ${ }^{2}$ Concord Repatriation General Hospital, Concord, New South Wales, Australia \\ Email: *Mohsen.Shafiei@health.nsw.gov.au
}

How to cite this paper: Shafiei, M., Beale, P. and Blinman, P. (2021) Five Year Survival Outcomes of Prospectively Recorded Cohort Data for Older Adults versus Younger Adults with Resected Primary Rectal Cancer. Journal of Cancer Therapy, 12, 437-452. https://doi.org/10.4236/jct.2021.127038

Received: March 22, 2021

Accepted: July 19, 2021

Published: July 22, 2021

Copyright $\odot 2021$ by author(s) and Scientific Research Publishing Inc. This work is licensed under the Creative Commons Attribution International License (CC BY 4.0).

http://creativecommons.org/licenses/by/4.0/ (c) (i) Open Access

\begin{abstract}
Background: Rectal cancer predominantly occurs in older adults. We aimed to compare the long-term outcomes of older adults ( $\geq 70$ years) versus younger adults ( $<70$ years) who had had a primary resection for stage I-IV rectal cancer. Methods: Consecutive patients who had resection of a primary rectal cancer between January 1, 2000 and December 31, 2010 were identified from a prospective database at the Concord Repatriation General Hospital and stratified into two age groups: $<70$ years and $\geq 70$ years. Age-related differences in patients, cancer, and treatment characteristics were determined by Chi-square tests. 5-year Overall Survival (OS) and Cancer-Specific Survival (CSS) were determined by the Kaplan-Meier method and by multivariable Cox regression analysis. Results: Of 714 included patients, the mean age was 65.8 years (range, 21 - 92 years). 407 (57\%) patients were aged $<70$ years and 307 (43\%) were aged $\geq 70$ years. Older age ( $>70$ years) predicted more comorbidity $(\mathrm{p}<$ $0.001)$ and earlier stage $(p=0.01)$. Of the patients with stage III rectal cancer, older adults ( $>70$ years), compared with younger adults $(<70$ years), received less neoadjuvant chemotherapy [7/86 (8.1\%) vs $25 / 147(17.0 \%), \mathrm{p}=0.058$ ], less neoadjuvant radiotherapy [8/86 (9.3\%) vs $42 / 147(28.6 \%), \mathrm{p}=0.001]$ and less adjuvant chemotherapy [30/86 (34.9\%) vs $117 / 147$ (79.6\%), $\mathrm{p}<0.001]$. Older age was associated with worse OS and CSS in stage III ( $p<0.001$ and $p$ $=0.02$ respectively). Adjuvant chemotherapy independently predicted improved OS $(\mathrm{p}<0.001)$ and CSS $(\mathrm{p}=0.008)$ regardless of age. Conclusion: Older adults who had had a resection of stage I-IV primary rectal cancer received less neoadjuvant and adjuvant therapy and had worse OS and CSS than their younger counterparts.
\end{abstract}


Keywords

Rectal Cancer, Chemotherapy, Radiotherapy, Overall Survival, Cancer Specific Survival

\section{Introduction}

Rectal cancer predominantly occurs in older adults with an increasing incidence with increasing age [1]. Worldwide, there were an estimated 704,000 new cases of rectal cancer in 2018 [2] with the highest risk in developed countries. In Australia, there were an estimated 5238 new cases of rectal cancer in 2019 with over half of these patients (58\%) aged over 65 years [3]. With increasing life expectancy and the general aging of the population [4], the number of older adults diagnosed with rectal cancer is expected to increase, making optimisation of the management of rectal cancer in older adults an important priority for clinicians involved in their care.

The treatment of locally advanced rectal cancer (stage II, $\geq$ T3-N0 or stage III, any $\mathrm{T} \geq \mathrm{N} 1$ ) has evolved over the last two decades. Surgery is the mainstay of curative treatment with the addition of neoadjuvant and/or adjuvant therapy for resectable locally advanced disease. For fit patients, one standard approach is tri-modality treatment with neoadjuvant radiotherapy \pm chemotherapy followed by a Total Mesorectal Excision (TME) and adjuvant chemotherapy. This approach is based on several randomized clinical trials that showed neoadjuvant radiotherapy \pm chemotherapy improved local control ranged from $7 \%(4.4 \%$ $11 \%, \mathrm{p}=0.004)$ to $16 \%(11 \%-27 \%, \mathrm{p}<0.001)$ without consistent improvement in Overall Survival (OS) [5] [6]. The addition of adjuvant chemotherapy improved Disease-Free Survival (DFS) (HR 0.59, 95\% CI 0.40 - 0.85) and distant recurrence (HR $0.61,95 \%$ CI 0.40 - 0.94) particularly in patients with a tumour $10-15 \mathrm{~cm}$ from the anal verge [7]. The NCCN and ESMO guidelines recommend adjuvant chemotherapy as standard treatment for all patients with locally advanced rectal cancer after neoadjuvant radiotherapy or Chemoradiotherapy (CRT) and surgery [8] [9].

Older adults with rectal cancer, compared with younger adults with rectal cancer, may be challenging to treat with triple modality therapy due to the intensity and toxicity of the treatment. Older adults have more comorbidities and geriatric syndromes such as falls, polypharmacy, cognitive impairment and malnutrition that reduce their fitness for standard cancer therapy [10] [11]. Older adults are also more likely to discontinue therapy earlier than younger adults due to the higher rates of treatment toxicity [12]. Older adults are less likely to be referred for neoadjuvant and adjuvant therapy for rectal cancer [13] and, when referred, they may not be offered similar treatment as their younger counterparts [13] [14] [15]. Another key factor affecting the management of older adults with rectal cancer is their underrepresentation in pertinent clinical 
trials. The abovementioned trials of neoadjuvant CRT and adjuvant chemotherapy in rectal cancer included mostly younger (median age of 60 - 61) and fitter adults (ECOG performance status of 0 or 1) rather than the frail, older adults typical of routine clinical practice [16]. This means little specific randomized evidence in older adults with rectal cancer to help clinicians guide their care.

Observational studies have a role in determining the impact of age on outcomes of rectal cancer when older adults are underrepresented in randomized clinical trials. The results of observational studies determining Overall Survival (OS) and Cancer-Specific Survival (CSS) for rectal cancer generally show worse OS with increasing age, but inconsistent results for CSS [17] [18] [19].

We conducted an observational study to determine the long-term outcomes of older adults who had had a resection of primary rectal cancer and their utilisation of neoadjuvant CRT and adjuvant chemotherapy, compared with their younger counterparts in our local institution. We hypothesized that older adults, compared with younger adults, had worse long-term outcomes and lower rates of utilisation of neoadjuvant and adjuvant therapy.

\section{Methods}

\subsection{Study Design}

Consecutive patients over the age of 18 who had undergone curative or palliative surgery for a diagnosis of rectal cancer at the Concord Repatriation General Hospital, Sydney, Australia between 2000 and 2011 were included. Data were extracted from a prospectively collected Colorectal Cancer (CRC) database maintained since 1971 and received approval of the Sydney Local Health District Ethics Committee (CH62/62011-136-P Chapuis HREC/11/CRGH206). This database included patient characteristics, comorbidity, presentation, investigations, pathology, neoadjuvant therapy, surgical management, complications, receipt of adjuvant therapy and follow-up data. This project included and explored the following variables: patient gender, previous history of colorectal cancer, number of comorbidities, cardiac comorbidity, resection at urgent operation, histological type, maximum surface dimension, staging, lymphatic vessel invasion, venous invasion, positive margin, neoadjuvant therapy and adjuvant chemotherapy. Patients were stratified to two age groups, $<70$ years and $\geq 70$ years, at the time of diagnosis.

\subsection{Statistical Analysis}

Patient demographics, tumour and treatment characteristics between the two age-groups ( $<70$ years and $\geq 70$ years) were compared by the use of the log-rank test. Demographic, tumour and treatment characteristics were compared with use of the chi-squared test for association for categorical factors. Kaplan-Meier method was used to construct overall and rectal cancer specific survival curves in patients with stage III rectal cancer. Results of patients in stage III rectal cancer only were analyzed due to the use of adjuvant chemotherapy in this stage in 
routine clinical practice. For 5-year CSS and 5-year OS analysis in patients with stage III rectal cancer, the two age groups ( $<70$ years and $\geq 70$ years) were further stratified by gender, resection at urgent operation, lymphatic vessel invasion, positive margin, venous invasion, number of comorbidities and receipt of neoadjuvant CRT and adjuvant chemotherapy. To determine the association between these factors and patient OS and CSS, multivariate cox regression analysis was performed. SPSS (version 24) was used for all statistical analyses. All p values were 2 -sided and values $<0.05$ were considered statistically significant.

\section{Results}

714 patients were included in the study. The mean age was 65.9 years (range, 21 - 92 years). 407 (57\%) patients were aged $<70$ years and 307 (43\%) were $\geq 70$ years. There were more males than females in both the younger $(271 / 407,67 \%)$ and older $(182 / 307,60 \%)$ age groups. Demographic information, presentation and treatment characteristics are presented in Table 1.

Older age group ( $\geq 70$ years) predicted more comorbidity $(\mathrm{p}<0.001)$, cardiac comorbidity $(\mathrm{p}<0.001)$, lymphatic vessel invasion $(\mathrm{p}=0.03)$, early stage tumour $(\mathrm{p}=0.01)$, less neoadjuvant radiotherapy ( $\mathrm{p} 0.001)$, less neoadjuvant chemotherapy $(\mathrm{p}<0.001)$ and less adjuvant chemotherapy (stage III only; $\mathrm{p}<0.001$ ).

In patients with stage III rectal cancer, older adults ( $\geq 70$ years), compared with younger adults ( $<70$ years), received less neoadjuvant chemotherapy [7/86 $(8.1 \%)$ vs $25 / 147(17.0 \%), p=0.058$ ], less neoadjuvant radiotherapy [8/86 (9.3\%) vs $42 / 147(28.6 \%), \mathrm{p}=0.001]$ and less adjuvant chemotherapy [8/86 (9.3\%) vs $42 / 147(28.6 \%), \mathrm{p}=0.001]$.

Table 1. Tumour and treatment characteristics stratified by age.

\begin{tabular}{|c|c|c|c|c|}
\hline \multirow[t]{4}{*}{ Characteristics } & \multicolumn{4}{|c|}{ Age group years } \\
\hline & Total & $<70$ & $\geq 70$ & $\mathrm{P}$ difference \\
\hline & $\mathrm{N}=714$ & $\mathrm{~N}=407$ & $\mathrm{~N}=307$ & between \\
\hline & Mean & Mean & Mean & $<70$ and $\geq 70$ \\
\hline \multicolumn{5}{|c|}{ Previous CRC resected } \\
\hline No & $702(98.3 \%)$ & $399(98.0 \%)$ & $303(98.7 \%)$ & \multirow[b]{2}{*}{$\mathrm{P}=0.49$} \\
\hline Yes & $12(1.7 \%)$ & $8(2 \%)$ & $4(1.3 \%)$ & \\
\hline \multicolumn{5}{|c|}{ No. of comorbidities } \\
\hline$\leq 1$ & $545(76.3 \%)$ & $341(83.8 \%)$ & $204(66.4 \%)$ & \multirow{2}{*}{$\mathrm{P}<0.001$} \\
\hline$>1$ & $169(23.7 \%)$ & $66(16.2 \%)$ & $103(33.6 \%)$ & \\
\hline \multicolumn{5}{|c|}{ Cardiac comorbidity ${ }^{*}$} \\
\hline No & $526(77.8 \%)$ & $355(89 \%)$ & $171(61.7 \%)$ & \multirow[b]{2}{*}{$\mathrm{P}<0.001$} \\
\hline Yes & $150(22.2 \%)$ & $44(11 \%)$ & $106(38.3 \%)$ & \\
\hline \multicolumn{5}{|c|}{ Resection at urgent operation } \\
\hline No & 707 (99\%) & $403(99 \%)$ & $304(99 \%)$ & \multirow{2}{*}{$\mathrm{P}=0.99$} \\
\hline Yes & $7(1 \%)$ & $4(1 \%)$ & $3(1 \%)$ & \\
\hline
\end{tabular}




\section{Continued}

\begin{tabular}{|c|c|c|c|c|}
\hline \multicolumn{5}{|c|}{ Histological type of primary } \\
\hline Adenocarcinoma & $661(92.6 \%)$ & $371(91.2 \%)$ & $290(94.5 \%)$ & \multirow{3}{*}{$\mathrm{P}=0.09$} \\
\hline Mucinous & & & & \\
\hline $\begin{array}{l}\text { Adenocarcinoma/ } \\
\text { Signet ring }\end{array}$ & $53(7.4 \%)$ & $36(8.8 \%)$ & $17(5.5 \%)$ & \\
\hline \multicolumn{5}{|c|}{ Distant metastasis } \\
\hline No & $621(87.0 \%)$ & $347(85.3 \%)$ & $274(89.3 \%)$ & \multirow{2}{*}{$\mathrm{P}=0.12$} \\
\hline Yes & $93(13.0 \%)$ & $60(14.7 \%)$ & $33(10.7 \%)$ & \\
\hline \multicolumn{5}{|c|}{ Lymphatic vessel permeation } \\
\hline No & $569(79.7 \%)$ & $313(76.9 \%)$ & $256(83.4 \%)$ & \multirow[b]{2}{*}{$\mathrm{P}=0.03$} \\
\hline Yes & $145(20.3 \%)$ & $94(23.1 \%)$ & $51(16.6 \%)$ & \\
\hline \multicolumn{5}{|c|}{ Venous invasion } \\
\hline None & $582(81.5 \%)$ & $326(80.1 \%)$ & $256(83.4 \%)$ & \multirow[b]{2}{*}{$\mathrm{P}=0.26$} \\
\hline Yes & $132(18.5 \%)$ & $81(19.9 \%)$ & $51(16.6 \%)$ & \\
\hline \multicolumn{5}{|c|}{ Positive margin } \\
\hline No & $667(93.4 \%)$ & $380(93.4 \%)$ & $287(93.4 \%)$ & \multirow{2}{*}{$\mathrm{P}=0.95$} \\
\hline Yes & $47(6.6 \%)$ & $20(6.5 \%)$ & $27(6.6 \%)$ & \\
\hline \multicolumn{5}{|c|}{ Preoperative radiotherapy } \\
\hline No & $594(83.2 \%)$ & $311(76.4 \%)$ & $283(92.2 \%)$ & \multirow[b]{2}{*}{$\mathrm{P}<0.001$} \\
\hline Yes & $120(16.8 \%)$ & $96(23.6 \%)$ & $24(7.8 \%)$ & \\
\hline \multicolumn{5}{|c|}{ Preoperative chemotherapy } \\
\hline No & $633(88.7 \%)$ & $344(84.5 \%)$ & $289(94.1 \%)$ & \multirow{2}{*}{$\mathrm{P}<0.001$} \\
\hline Yes & $81(11.3 \%)$ & $63(15.5 \%)$ & $18(5.9 \%)$ & \\
\hline \multicolumn{5}{|c|}{ Postoperative radiotherapy } \\
\hline No & $691(96.8 \%)$ & $395(97.1 \%)$ & $296(96.4 \%)$ & \multirow[b]{2}{*}{$\mathrm{P}=0.64$} \\
\hline Yes & $23(3.2 \%)$ & $12(2.9 \%)$ & $11(3.6 \%)$ & \\
\hline \multicolumn{5}{|c|}{ Postoperative chemotherapy } \\
\hline No & $487(68.2 \%)$ & $225(55.3 \%)$ & $262(85.3 \%)$ & \multirow{2}{*}{$\mathrm{P}<0.001$} \\
\hline Yes & $227(31.8 \%)$ & $182(44.7 \%)$ & $45(14.7 \%)$ & \\
\hline \multicolumn{5}{|c|}{ TNM stage } \\
\hline Stage I & $187(26.2 \%)$ & $95(23.3 \%)$ & $92(30.0 \%)$ & \multirow{4}{*}{$\mathrm{P}=0.01$} \\
\hline Stage II & $201(28.2 \%)$ & $105(25.8 \%)$ & $96(31.3 \%)$ & \\
\hline Stage III & $233(32.6 \%)$ & $147(36.1 \%)$ & $86(28.0 \%)$ & \\
\hline Stage IV & $93(13.0 \%)$ & 60 (14.7\%) & $33(10.7 \%)$ & \\
\hline
\end{tabular}

*There were 38 missing cases for New York Heart Association evaluation. 
The 5-year OS and 5-year CSS between the two age groups stratified by cancer stage are shown in Table 2. Kaplan-Meier survival curves are presented in Figures 1-4. Five-year OS was significantly lower in the older age group irrespective of cancer stage $(\mathrm{p}<0.001)$ (Table 2 , Figure 1$)$. In patients with stage III rectal cancer, increasing age group was associated with worse 5-year OS $[44.2 \%(\geq 70$ years) vs $71.9 \%$ ( $<70$ years), $\mathrm{p}<0.001]$, and worse 5 -year CSS $[62.3 \%$ ( $\geq 70$ years) vs $76.2 \%$ ( $<70$ years), $\mathrm{p}=0.02$ ] (Figure 3 and Figure 4 ).

Table 2. 5-year overall and cancer specific survival after surgery by age group and pathological stage.

\begin{tabular}{|c|c|c|c|c|c|c|}
\hline Stage & Age group & No of cases & $\begin{array}{l}\text { 5-year } \\
\text { OS rate }\end{array}$ & $P$ value & $\begin{array}{l}\text { 5-year } \\
\text { CSS rate }\end{array}$ & $P$ value \\
\hline \multirow{3}{*}{ Stage I } & $<70$ & 95 & $94.7 \%$ & & $97.8 \%$ & \\
\hline & $\geq 70$ & 92 & $72.8 \%$ & & $91.1 \%$ & \\
\hline & All & 187 & & & & \\
\hline \multirow{4}{*}{ Stage II } & $<70$ & 105 & $81.9 \%$ & & $87.3 \%$ & \\
\hline & $\geq 70$ & 96 & $60.0 \%$ & & $82.6 \%$ & \\
\hline & All & 201 & & & & \\
\hline & & & & $<0.001$ & & 0.001 \\
\hline \multirow{3}{*}{ Stage III } & $<70$ & 147 & $71.9 \%$ & & $76.2 \%$ & \\
\hline & $\geq 70$ & 86 & $44.2 \%$ & & $62.3 \%$ & \\
\hline & All & 233 & & & & \\
\hline \multirow{3}{*}{ Stage IV } & $<70$ & 60 & $11.7 \%$ & & $11.9 \%$ & \\
\hline & $\geq 70$ & 33 & $0 \%$ & & $0 \%$ & \\
\hline & All & 93 & & & & \\
\hline
\end{tabular}

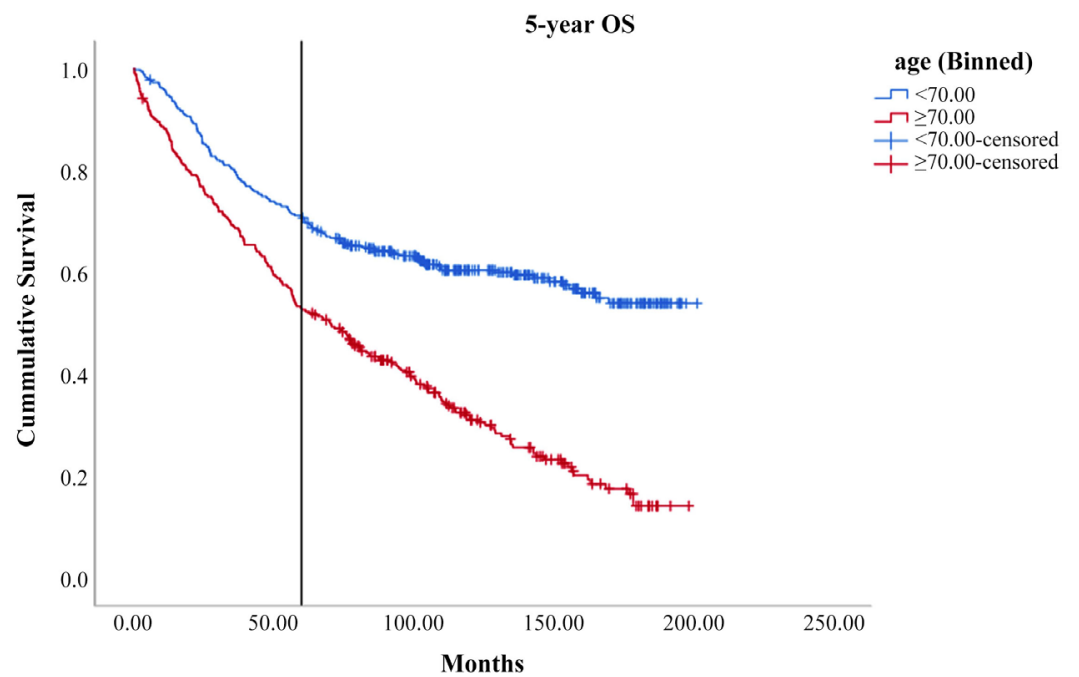

Figure 1 . OS curve by age group for all stages. $\mathrm{P}<0.001$. 


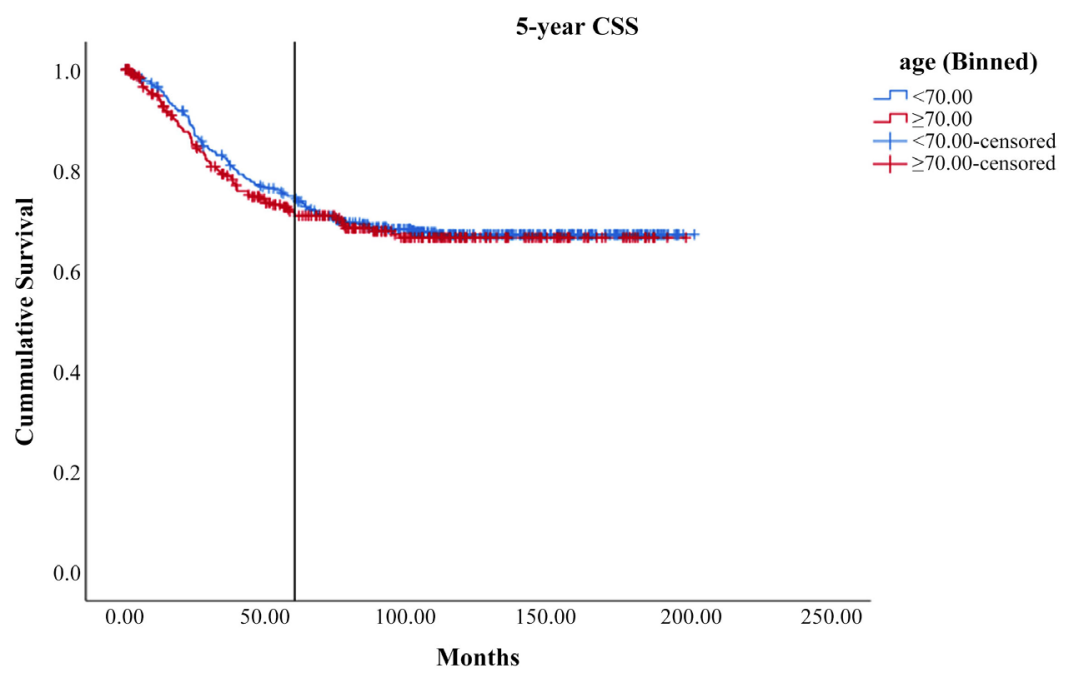

Figure 2. CSS curve by age group for all stages. $\mathrm{P}=0.65$.

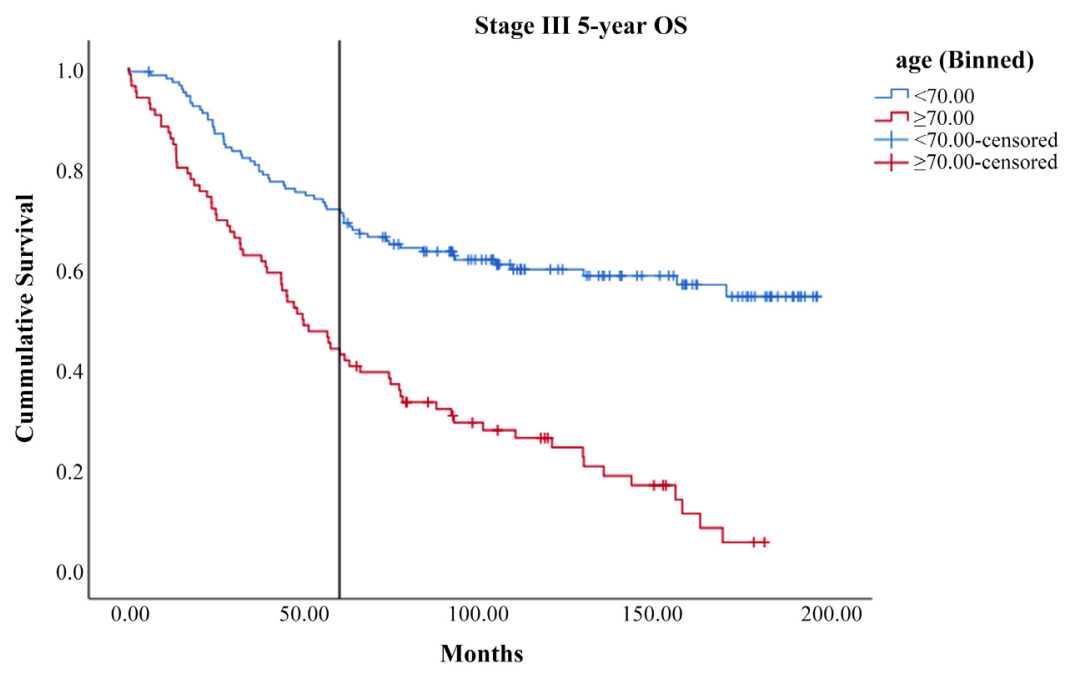

Figure 3. OS curve by age group for stage III. $\mathrm{P}<0.001$.

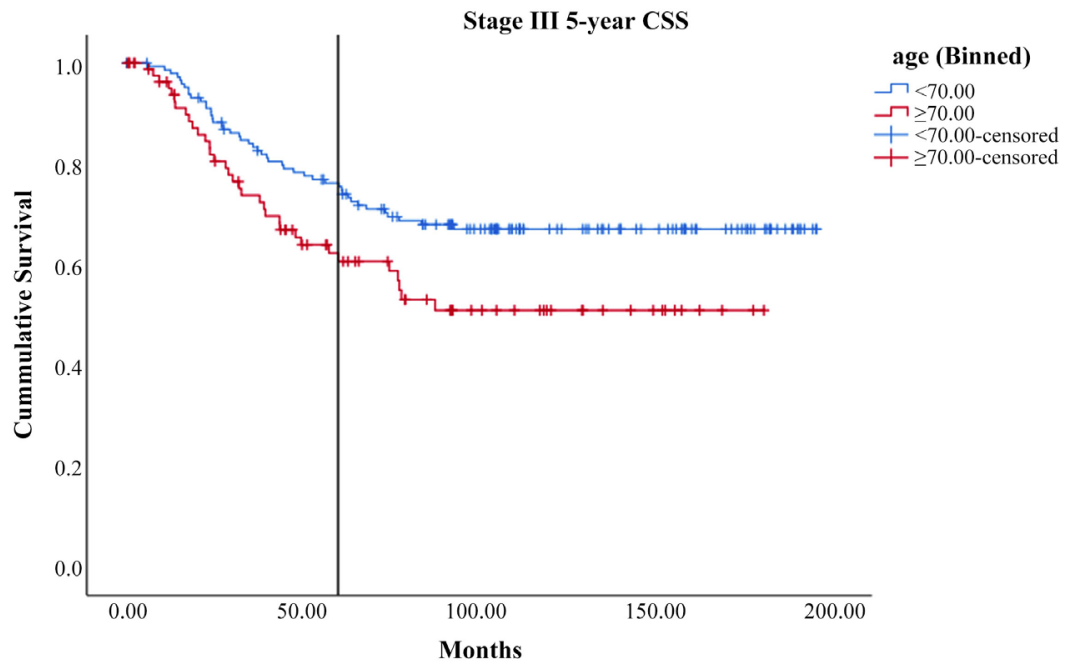

Figure 4. CSS curve by age group for stage III. $\mathrm{P}=0.02$. 
In patients with stage III rectal cancer, bivariate predictors of improved OS were age $<70$ years $(\mathrm{p}<0.001)$, no lymphatic vessel invasion $(\mathrm{p}<0.001)$, no positive margin $(\mathrm{p}<0.001)$, receiving adjuvant chemotherapy and less comorbidity $(\mathrm{p}=0.002)($ Table 3$)$. Neoadjuvant radiotherapy did not improve OS $(\mathrm{p}=$ $0.41)$ but significantly improved CSS $(\mathrm{p}=0.038)$ (Figure 5$)$. On multivariable analysis, improved OS was independently predicted by age $<70$ years (hazard ratio, 0.44, p < 0.001), no lymphatic vessel invasion (hazard ratio, 0.47, p < 0.001 ), no positive margin (hazard ratio, $0.23 \mathrm{p}<0.001$ ) and receiving adjuvant chemotherapy (hazard ratio, $0.50, \mathrm{p}=0.001$ ). Improved CSS was predicted by adjuvant chemotherapy in stage III rectal cancer $(\mathrm{p}=0.008)$ (Figure 6$)$.

Table 3. Bivariate and multivariable survival analysis for only stage III rectal cancer.

\begin{tabular}{|c|c|c|c|c|c|}
\hline Variable & Number & $\begin{array}{l}\text { Bivariate hazard } \\
\text { Ratio }(95 \% \mathrm{CI})\end{array}$ & $\mathrm{p}$ & $\begin{array}{l}\text { Multivariable hazard } \\
\text { Ratio }(95 \% \mathrm{CI})\end{array}$ & $\mathrm{p}$ \\
\hline $\begin{array}{l}\text { Female } \\
\text { Male }\end{array}$ & $\begin{array}{c}86 \\
147\end{array}$ & $1.13(0.79-1.63)$ & 0.47 & & \\
\hline $\begin{array}{l}\text { Age }<70 \text { years } \\
\text { Age } \geq 70 \text { years }\end{array}$ & $\begin{array}{c}147 \\
86\end{array}$ & $0.34(0.24-0.48)$ & $<0.001$ & $0.44(0.30-0.65)$ & $<0.001$ \\
\hline $\begin{array}{l}\text { No Previous CRC } \\
\text { Previous CRC }\end{array}$ & $\begin{array}{c}228 \\
5\end{array}$ & $0.61(0.19-1.93)$ & 0.40 & & \\
\hline $\begin{array}{l}\text { No Resection at urgent operation } \\
\text { Resection at urgent operation }\end{array}$ & $\begin{array}{c}230 \\
3\end{array}$ & $0.44(0.11-1.77)$ & 0.25 & & \\
\hline $\begin{array}{l}\text { No Venous invasion } \\
\text { Venous invasion }\end{array}$ & $\begin{array}{c}181 \\
52\end{array}$ & $0.70(0.48-1.04)$ & 0.08 & & \\
\hline $\begin{array}{l}\text { No lymphatic vessel invasion } \\
\text { Lymphatic vessel invasion }\end{array}$ & $\begin{array}{c}156 \\
77\end{array}$ & $0.49(0.34-0.69)$ & $<0.001$ & $0.47(0.32-0.68)$ & $<0.001$ \\
\hline $\begin{array}{l}\text { No positive margin } \\
\text { Positive margin }\end{array}$ & $\begin{array}{c}212 \\
21\end{array}$ & $0.16(0.10-0.26)$ & $<0.001$ & $0.23(0.14-0.39)$ & $<0.001$ \\
\hline $\begin{array}{c}\text { Adenocarcinoma } \\
\text { Mucinous adenoCa/ Signet ring }\end{array}$ & $\begin{array}{c}208 \\
25\end{array}$ & $0.68(0.41-1.13)$ & 0.14 & & \\
\hline $\begin{array}{l}\text { Neoadjuvant radiotherapy } \\
\text { No neoadjuvant radiotherapy }\end{array}$ & $\begin{array}{c}50 \\
183\end{array}$ & $1.19(0.78-1.80)$ & 0.41 & & \\
\hline $\begin{array}{l}\text { Neoadjuvant chemotherapy } \\
\text { No neoadjuvant chemotherapy }\end{array}$ & $\begin{array}{c}32 \\
201\end{array}$ & $1.07(0.64-1.78)$ & 0.79 & & \\
\hline $\begin{array}{l}\text { Adjuvant radiotherapy } \\
\text { No adjuvant radiotherapy }\end{array}$ & $\begin{array}{c}14 \\
219\end{array}$ & $1.40(0.73-2.67)$ & 0.31 & & \\
\hline $\begin{array}{l}\text { Adjuvant chemotherapy } \\
\text { No adjuvant chemotherapy }\end{array}$ & $\begin{array}{c}147 \\
86\end{array}$ & $0.34(0.24-0.50)$ & $<0.001$ & $0.50(0.34-0.74)$ & 0.001 \\
\hline $\begin{array}{l}\text { Number of nodes examined }<12 \\
\text { Number of nodes examined } \geq 12\end{array}$ & $\begin{array}{c}60 \\
173\end{array}$ & $1.30(0.89-1.90)$ & 0.17 & & \\
\hline $\begin{array}{l}\text { Number of comorbidities } \leq 1 \\
\text { Number of comorbidities }>1\end{array}$ & $\begin{array}{c}179 \\
54\end{array}$ & $0.55(0.38-0.81)$ & 0.002 & $0.76(0.51-1.12)$ & 0.16 \\
\hline
\end{tabular}

CRC, Colorectal cancer. 


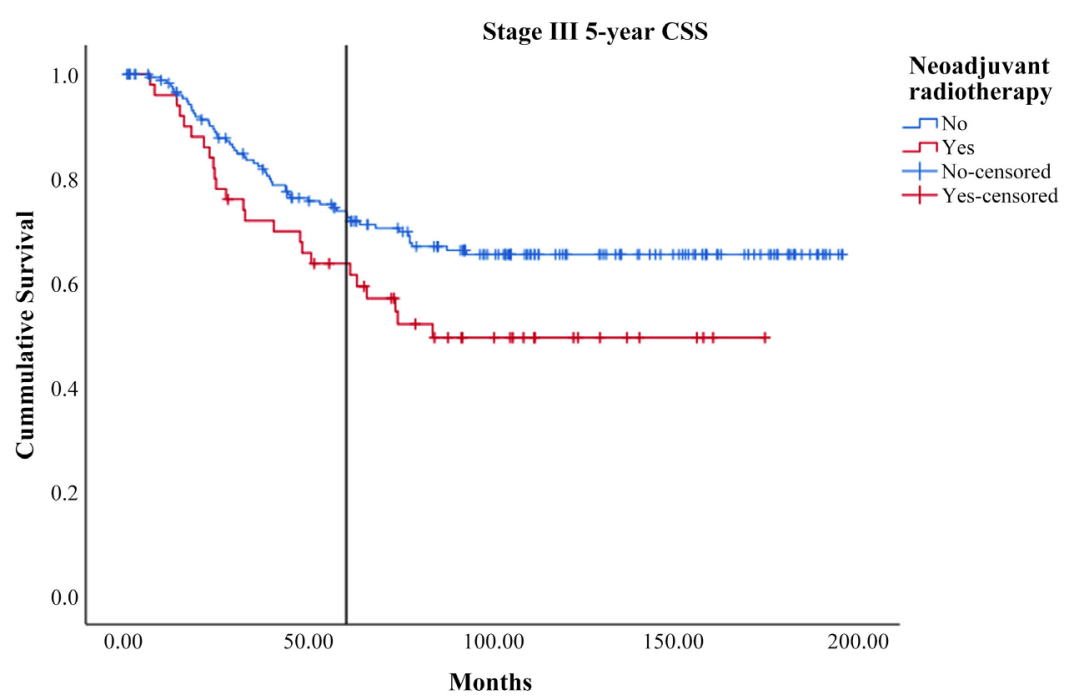

Figure 5. CSS curve by neoadjuvant radiotherapy in stage III rectal cancer. $\mathrm{P}=$ 0.038 .

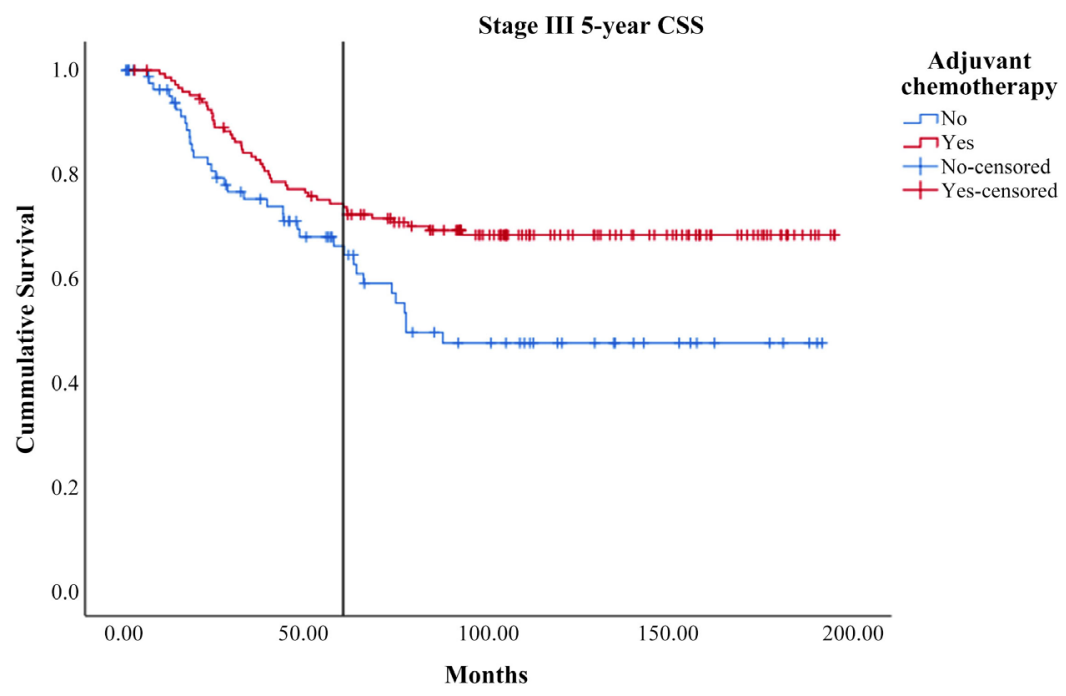

Figure 6. CSS curve by adjuvant chemotherapy in stage III rectal cancer. $\mathrm{P}=$ 0.008 .

\section{Discussion}

The key findings of our study were that older adults ( $\geq 70$ years), compared with younger adults ( $<70$ years), who had had a resection of primary rectal cancer of stage I to IV had higher comorbidity and cardiac comorbidity, more lymphatic vessel invasion and more early stage cancers. Older adults, compared with younger adults, received less neoadjuvant radiotherapy, less neoadjuvant chemotherapy and less adjuvant chemotherapy. 5-year OS declined significantly with the increasing age group. 5-year CSS was significantly worse in older adults with stage III rectal cancer.

The survival outcomes in our study are similar to other published studies. Chang et al. conducted an observational study using the Surveillance, Epidemi- 
ology, and End Results (SEER) database to examine more than 21,000 patients with locally advanced rectal cancer and found a $31 \%$ increase in the relative risk for cancer-specific mortality with each 5 -year increase in age $\geq 70$ years $(\mathrm{RR}=$ 1.31; 95\% CI, 1.25 - 1.36; P < 0.0001) [18]. Kotake et al. studied included 16,147 patients with rectal cancer in a large study from the Japanese cancer registry and found older age predicted worse 5 -year OS (50\% in $\geq 80$ years vs $73 \%$ in $50-64$ years, $\mathrm{p}<0.001)$ and worse 5 -year CSS $(65 \%$ in $\geq 80$ years vs $76 \%$ in $50-64$ years, $\mathrm{p}<0.001$ ) [17]. Jung et al. studied 15,104 patients with rectal cancer from the Swedish Rectal Cancer Registry 1995-2004 of whom more than 11,000 had had curative surgery (stages I-IV). Older adults ( $\geq 75$ years), compared with younger adults ( $<75$ years), had worse 5 -year OS $(0.52,95 \%$ CI, $0.50-0.54$ vs $0.62,95 \%$ CI, $0.61-0.63$ ) [19]. Devon et al. studied 373 adults undergoing curative surgery for their rectal cancer at the Mount Sinai Hospital, Canada between 1997 and 2006. Older adults (aged $>75$ years), compared with younger adults (aged 50 - 75 years), had worse 5 -year OS $(68.7 \%$ vs $57.3 \%, \mathrm{p}=0.036)$ but no difference in 5-year CSS (74.0\% vs. $74.7 \%, \mathrm{p}=0.277)$ [20]. Similarly, Widdison et al. studied 218 patients with rectal cancer and showed older age was not a predictor of worse 5 -year CSS (72\% for younger and older groups) [21].

It was unsurprising that older adults had worse OS in our study, like in the observational studies discussed above, given competing risks for death in older adults. More concerning was that CSS, or the chance of surviving cancer in the absence of other causes of death, was worse for older adults in stage III rectal cancer. Possible reasons for this result highlighted by our study are increased comorbidities and low utilisation rates of neoadjuvant and adjuvant therapy. Other possible reasons include increased toxicity from radiotherapy and chemotherapy and increased post-surgical complications.

The utilisation of neoadjuvant radiotherapy (7.8\%) and neoadjuvant chemotherapy (5.9\%) in older adults in our study was low, however, similar to other studies [17] [19]. The role of neoadjuvant radiotherapy and CRT in rectal cancer, however, is now well established. Multiple randomized trials and population based studies have shown that neoadjuvant radiotherapy and CRT improve local control in patients aged $>70$ years [6] [22] [23] [24] [25]. The large Swedish Rectal Cancer Study Group trial $(\mathrm{n}=1168)$ showed neoadjuvant radiotherapy ( $25 \mathrm{~Gy}$ in 5 fractions), compared with surgery alone, reduced local recurrence by $16 \%$ (from $27 \%$ to $11 \%, \mathrm{p}<0.001$ ) and improved both five-year OS by $10 \%(48 \%$ to $58 \%, \mathrm{p}=0.004)$ and CSS by $9 \%(65 \%$ to $74 \%, \mathrm{p}=0.002)$ (ref Swedish rectal trial). One possible explanation for the low utilisation rates in our study was the dates of data extraction being 2000-2011 (to allow for 5 years of follow-up for survival outcomes) when neoadjuvant radiotherapy \pm chemotherapy for older adults was likely a less accepted standard of care. Utilisation rates of neoadjuvant radiotherapy for rectal cancer for older adults have likely increased over time as clinicians have become familiar with the treatment and are generally more confident treating older adults with cancer. The older observational studies such as 
Kotake et al. (1995 to 2004) showed rates of $0.3 \%$ in patients aged $\geq 80$ years and $34 \%$ in patients aged $\geq 75$ years by Jung et al. (1995 to 2004) [7] [26]. Later studies such as Zhao et al. that analyzed rectal cancer data from the SEER database between 2004 and 2016, showed a utilisation rate of neoadjuvant radiotherapy of $53 \%$ for patients aged $>60$ years, lower than the $67 \%$ rate of patients aged $\leq 60$ years [27]. Other reasons for the low utilisation rates include patient preferences for no neoadjuvant and/or adjuvant therapy, and patient and clinician concerns about excess toxicity such as faecal incontinence and sexual dysfunction, which are more pronounced in older patients [28] [29] [30].

In our study, older adults with rectal cancer received less adjuvant chemotherapy $(9.3 \%)$ than younger adults $(28.6 \%)$ with rectal cancer as in previous studies [31]. Irrespective of age, there is no clear OS benefit of adjuvant chemotherapy for rectal cancer, and the treatment is largely a translation from the DFS and OS benefit of adjuvant chemotherapy in colon cancer [7] [31] [32] [33] [34] [35]. A meta-analysis of four pivotal randomized control trials examining the benefit of adjuvant chemotherapy for patients with locally advanced rectal cancer demonstrated that adjuvant 5-fluorouracil/capecitabine improves DFS (HR 0.59, 95\% CI: $0.40-0.85, \mathrm{p}=0.005$ ) and rate of distant recurrence (HR 0.61, 95\% CI: 0.40 $0.94, \mathrm{p}=0.025)$ in those patients with a tumour 10 to $15 \mathrm{~cm}$ above the anal verge but no improvement in OS (HR 0.97, 95\% CI: $0.81-1.17, \mathrm{p}=0.775$ ) [7]. Common clinical practice, supported by guidelines, is four months of adjuvant chemotherapy for patients who had long course CRT and six months of adjuvant chemotherapy for patients who have not had neoadjuvant therapy [8].

Possible reasons for the low utilisation rates in our study include the paucity of robust evidence supporting the benefit of such therapy in patients of all ages and in older adults (>70 years), referrer bias against the treatment resulting in reduced referrals for adjuvant chemotherapy, and concerns about the increased toxicity of chemotherapy in older adults [36]. Fit older adults with rectal cancer, however, benefit equally from adjuvant chemotherapy without a significant increase in toxicity [37].

Increasing treatment utilisation in older adults with rectal cancer involves optimal assessment of their fitness for treatment to minimise their exclusion from treatment based on their chronological age. This is particularly important in older adults with stage III rectal cancer where the worse CSS in our study highlights the need to improve outcomes and where tri-modality treatment, requiring careful patient selection, is a standard of care. Optimal assessment of older adults can be achieved by the use of formal geriatric assessments and risk predicting tools, as recommended by ASCO guidelines [38] [39]. Integrated geriatric assessment in the care of older adults with cancer has recently been shown to improve quality of life, reduce hospital admissions and reduce early discontinuation of anti-cancer therapy [40] [41] [42]. The key ways to improve treatment utilisation in older adults with rectal cancer include conducting trials and studies specific to older adults, for example, the optimal dosing of adjuvant chemotherapy. 
The main strength of our study is the prospective, large surgical database with minimal missing data. Limitations of our study include the database involving a single institution meaning that the surgical and oncological management, patient selection, surgical techniques, pre-operative and post-operative care, and selection for neoadjuvant radiotherapy or chemo-radiotherapy and adjuvant chemotherapy may differ from other institutions or health care settings. Details of radiotherapy (dose, fractionation, completion) and chemotherapy (regimen, dose, toxicities, completion) were not readily available and required manual searching through medical records for which the study was not adequately resourced. The generalisability of the study is limited due to the inclusion of patients who had had a resection of primary rectal cancer and hence excludes patients who were not suitable or fit for surgery or who chose not to have surgery.

In conclusion, older adults who had a resection of a stage I-IV rectal cancer had higher comorbidity, cardiac comorbidity, more lymphatic vessel invasion, early stage tumour, and received less neoadjuvant radiotherapy, less neoadjuvant chemotherapy and less adjuvant chemotherapy. Older adults had worse OS and worse CSS in stage III disease. These results highlight the need to optimise the treatment of older adults with rectal cancer and ways to increase the utilisation of adjuvant chemotherapy.

\section{Acknowledgements}

The authors would like to thank Professor Pierre Chapuis, Dr. Owen Dent and Gael Sinclair who assisted with the provision of the data from the Concord Repatriation General Hospital database on resected colorectal cancers.

\section{Authors' Disclosures}

The authors of this manuscript have no relevant financial or other relationships to disclose.

\section{Funding}

MS was supported by a Sydney Catalyst Postgraduate Research PhD scholarship.

\section{Conflicts of Interest}

The authors of this manuscript have no relevant affiliations or financial involvement with any organization or entity with a financial interest with the subject matter or materials discussed.

\section{References}

[1] Matanoski, G., Tao, X., Almon, L., Adade, A.A. and Davies-Cole, J.O. (2006) Demographics and Tumor Characteristics of Colorectal Cancers in the United States, 1998-2001. Cancer, 107, 1112-1120. https://doi.org/10.1002/cncr.22008

[2] Society, A.C. (2018) Global Cancer Statistics 2018: GLOBOCAN Estimates of Incidence and Mortality Worldwide for 36 Cancers in 185 Countries. 
[3] Australia C (2019) Cancer Incidence. https://ncci.canceraustralia.gov.au/diagnosis/cancer-incidence/cancer-incidence

[4] Crimmins, E.M. (2015) Lifespan and Healthspan: Past, Present, and Promise. The Gerontologist, 55, 901-911. https://doi.org/10.1093/geront/gnv130

[5] Quirke, P., Steele, R., Monson, J., Grieve, R., Khanna, S., Couture, J., O'Callaghan, C., et al. (2009) Effect of the Plane of Surgery Achieved on Local Recurrence in Patients with Operable Rectal Cancer: A Prospective Study Using Data from the MRC CR07 and NCIC-CTG CO16 Randomised Clinical Trial. Lancet (London, England), 373, 821-828. https://doi.org/10.1016/S0140-6736(09)60485-2

[6] Cedermark, B., Dahlberg, M., Glimelius, B., Påhlman, L., Rutqvist, L.E. and Wilking, N. (1997) Improved Survival with Preoperative Radiotherapy in Resectable Rectal Cancer. The New England Journal of Medicine, 336, 980-987.

https://doi.org/10.1056/NEJM199704033361402

[7] Breugom, A.J., Swets, M., Bosset, J.F., Collette, L., Sainato, A., Cionini, L., Glynne-Jones, R., et al. (2015) Adjuvant Chemotherapy after Preoperative (Chemo) radiotherapy and Surgery for Patients with Rectal Cancer: A Systematic Review and Meta-Analysis of Individual Patient Data. The Lancet Oncology, 16, 200-207.

https://doi.org/10.1016/S1470-2045(14)71199-4

[8] Network NCC (2020) NCCN Clinical Practice Guidelines in Oncology. Rectal Cancer. https://www.nccn.org/professionals/physician gls/pdf/rectal.pdf

[9] Oncology ESfM (2020) Rectal Cancer: ESMO Clinical Practice Guidelines. https://www.esmo.org/guidelines/gastrointestinal-cancers/rectal-cancer

[10] Hurria, A., Browner, I.S., Cohen, H.J., Denlinger, C.S., deShazo, M., Extermann, M., Ganti, A.K., et al. (2012) Senior Adult Oncology. Journal of the National Comprehensive Cancer Network. JNCCN, 10, 162-209. https://doi.org/10.6004/jnccn.2012.0019

[11] Farrington, N., Richardson, A. and Bridges, J. (2020) Interventions for Older People Having Cancer Treatment: A Scoping Review. Journal of Geriatric Oncology, 11, 769-783. https://doi.org/10.1016/j.jgo.2019.09.015

[12] Kahn, K.L., Adams, J.L., Weeks, J.C., Chrischilles, E.A., Schrag, D., Ayanian, J.Z., Kiefe, C.I., et al. (2010) Adjuvant Chemotherapy Use and Adverse Events among Older Patients with Stage III Colon cancer. JAMA, 303, 1037-1045. https://doi.org/10.1001/jama.2010.272

[13] Luo, R., Giordano, S.H., Freeman, J.L., Zhang, D. and Goodwin, J.S. (2006) Referral to Medical Oncology: A Crucial Step in the Treatment of Older Patients with Stage III Colon Cancer. The Oncologist, 11, 1025-1033. https://doi.org/10.1634/theoncologist.11-9-1025

[14] Samet, J., Hunt, W.C., Key, C., Humble, C.G. and Goodwin, J.S. (1986) Choice of Cancer Therapy Varies with Age of Patient. JAMA, 255, 3385-3390. https://doi.org/10.1001/jama.1986.03370240055036

[15] Goodwin, J.S., Hunt, W.C. and Samet, J.M. (1993) Determinants of Cancer Therapy in Elderly Patients. Cancer, 72, 594-601. https://doi.org/10.1002/1097-0142(19930715)72:2<594::AID-CNCR2820720243>3.0 .CO;2-\#

[16] Moth, E.B., Kiely, B.E., Martin, A., Naganathan, V., Della-Fiorentina, S., Honeyball, F., Zielinski, R., et al. (2019) Older Adults' Preferred and Perceived Roles in Decision-Making about Palliative Chemotherapy, Decision Priorities and Information Preferences. Journal of Geriatric Oncology, 11, 626-632. https://doi.org/10.1200/JCO.2019.37.15 suppl.11546 
[17] Kotake, K., Asano, M., Ozawa, H., Kobayashi, H. and Sugihara, K. (2015) Tumour Characteristics, Treatment Patterns and Survival of Patients Aged 80 Years or Older with Colorectal Cancer. Colorectal Disease, 17, 205-215. https://doi.org/10.1111/codi.12826

[18] Chang, G.J., Skibber, J.M., Feig, B.W. and Rodriguez-Bigas, M. (2007) Are We Undertreating Rectal Cancer in the Elderly? An Epidemiologic Study. Annals of Surgery, 246, 215-221. https://doi.org/10.1097/SLA.0b013e318070838f

[19] Jung, B., Pahlman, L., Johansson, R. and Nilsson, E. (2009) Rectal Cancer Treatment and Outcome in the Elderly: An Audit Based on the Swedish Rectal Cancer Registry 1995-2004. BMC Cancer, 9, 68. https://doi.org/10.1186/1471-2407-9-68

[20] Devon, K.M., Vergara-Fernandez, O., Victor, J.C. and McLeod, R.S. (2009) Colorectal Cancer Surgery in Elderly Patients: Presentation, Treatment, and Outcomes. Diseases of the Colon and Rectum, 52, 1272-1277. https://doi.org/10.1007/DCR.0b013e3181a74d2e

[21] Widdison, A.L., Barnett, S.W. and Betambeau, N. (2011) The Impact of Age on Outcome after Surgery for Colorectal Adenocarcinoma. Annals of the Royal College of Surgeons of England, 93, 445-450. https://doi.org/10.1308/003588411X587154

[22] Gérard, J.P., Conroy, T., Bonnetain, F., Bouché, O., Chapet, O., Closon-Dejardin, M.T., Untereiner, M., et al. (2006) Preoperative Radiotherapy with or without Concurrent Fluorouracil and Leucovorin in T3-4 Rectal Cancers: Results of FFCD 9203. Journal of Clinical Oncology. Official Journal of the American Society of Clinical Oncology, 24, 4620-4625. https://doi.org/10.1200//CO.2006.06.7629

[23] Bosset, J.F., Calais, G., Mineur, L., Maingon, P., Radosevic-Jelic, L., Daban, A., Bardet, E., et al. (2005) Enhanced Tumorocidal Effect of Chemotherapy with Preoperative Radiotherapy for Rectal Cancer: Preliminary Results-EORTC 22921. Journal of Clinical Oncology: Official Journal of the American Society of Clinical Oncology, 23, 5620-5627. https://doi.org/10.1200/JCO.2005.02.113

[24] Boulis-Wassif, S., Gerard, A., Loygue, J., Camelot, D., Buyse, M. and Duez, N. (1984) Final Results of a Randomized Trial on the Treatment of Rectal Cancer with Preoperative Radiotherapy Alone or in Combination with 5-Fluorouracil, Followed by Radical Surgery. Trial of the European Organization on Research and Treatment of Cancer Gastrointestinal Tract Cancer Cooperative Group. Cancer, 53, 1811-1818. https://doi.org/10.1002/1097-0142(19840501)53:9<1811::AID-CNCR2820530902>3. $\underline{0 . \mathrm{CO} ; 2-\mathrm{H}}$

[25] McCarthy, K., Pearson, K., Fulton, R. and Hewitt, J. (2012) Pre-Operative Chemoradiation for Non-Metastatic Locally Advanced Rectal Cancer. The Cochrane Database of Systematic Reviews, 12, Cd008368.

https://doi.org/10.1002/14651858.CD008368.pub2

[26] Holm, T., Rutqvist, L.E., Johansson, H. and Cedermark, B. (1996) Postoperative Mortality in Rectal Cancer Treated with or without Preoperative Radiotherapy: Causes and Risk Factors. The British Journal of Surgery, 83, 964-968. https://doi.org/10.1002/bjs. 1800830725

[27] Zhao, F., Wang, J., Yu, H., Cheng, X., Li, X., Zhu, X., Xu, X., et al. (2020) Neoadjuvant Radiotherapy Improves Overall Survival for T3/4N+M0 Rectal Cancer Patients: A Population-Based Study of 20300 Patients. Radiation Oncology (London, England), 15, 49. https://doi.org/10.1186/s13014-020-01497-4

[28] Dahlberg, M., Glimelius, B., Graf, W. and Pahlman, L. (1998) Preoperative Irradiation Affects Functional Results after Surgery for Rectal Cancer: Results from a Randomized Study. Diseases of the Colon and Rectum, 41, 543-549.

https://doi.org/10.1007/BF02235256 
[29] Lange, M.M., den Dulk, M., Bossema, E.R., Maas, C.P., Peeters, K.C., Rutten, H.J., Klein Kranenbarg, E., et al. (2007) Risk Factors for Faecal Incontinence after Rectal Cancer Treatment. The British Journal of Surgery, 94, 1278-1284. https://doi.org/10.1002/bjs.5819

[30] Birgisson, H., Pahlman, L., Gunnarsson, U. and Glimelius, B. (2007) Late Adverse Effects of Radiation Therapy for Rectal Cancer-A Systematic Overview. Acta Oncologica (Stockholm, Sweden), 46, 504-516. https://doi.org/10.1080/02841860701348670

[31] Liu, S.L., O’Brien, P., Zhao, Y., Hopman, W.M., Lamond, N. and Ramjeesingh, R. (2018) Adjuvant Treatment in Older Patients with Rectal Cancer: A Population-Based Review. Current Oncology, 25, e499-e506.

https://doi.org/10.3747/co.25.4102

[32] Bosset, J.F., Collette, L., Calais, G., Mineur, L., Maingon, P., Radosevic-Jelic, L., Daban, A., et al. (2006) Chemotherapy with Preoperative Radiotherapy in Rectal Cancer. The New England Journal of Medicine, 355, 1114-1123. https://doi.org/10.1056/NEJMoa060829

[33] Sainato, A., Cernusco Luna Nunzia, V., Valentini, V., De Paoli, A., Maurizi, E.R., Lupattelli, M., Aristei, C., et al. (2014) No Benefit of Adjuvant Fluorouracil Leucovorin Chemotherapy after Neoadjuvant Chemoradiotherapy in Locally Advanced Cancer of the Rectum (LARC): Long Term Results of a Randomized Trial (I-CNR-RT). Radiotherapy and Oncology. Journal of the European Society for Therapeutic Radiology and Oncology, 113, 223-229. https://doi.org/10.1016/j.radonc.2014.10.006

[34] Breugom, A.J., van Gijn, W., Muller, E.W., Berglund, Å., van den Broek, C.B., Fokstuen, T., Gelderblom, H., et al. (2015) Adjuvant Chemotherapy for Rectal Cancer Patients Treated with Preoperative (Chemo)radiotherapy and Total Mesorectal Excision: A Dutch Colorectal Cancer Group (DCCG) Randomized Phase III Trial. Annals of Oncology: Official Journal of the European Society for Medical Oncology, 26, 696-701. https://doi.org/10.1093/annonc/mdu560

[35] Glynne-Jones, R., Counsell, N., Quirke, P., Mortensen, N., Maraveyas, A., Meadows, H.M., Ledermann, J., et al. (2014) Chronicle: Results of a Randomised Phase III Trial in Locally Advanced Rectal Cancer after Neoadjuvant Chemoradiation Randomising Postoperative Adjuvant Capecitabine plus Oxaliplatin (XELOX) versus Control. Annals of Oncology: Official Journal of the European Society for Medical Oncology, 25, 1356-1362. https://doi.org/10.1093/annonc/mdu147

[36] Nitsche, U., Stöss, C. and Friess, H. (2017) Effect of Adjuvant Chemotherapy on Elderly Colorectal Cancer Patients: Lack of Evidence. Gastrointestinal Tumors, 4, 11-19. https://doi.org/10.1159/000479318

[37] Millan, M., Merino, S., Caro, A., Feliu, F., Escuder, J. and Francesch, T. (2015) Treatment of Colorectal Cancer in the Elderly. World Journal of Gastrointestinal Oncology, 7, 204-220. https://doi.org/10.4251/wjgo.v7.i10.204

[38] Hurria, A. and Siccion, E.P. (2014) Assessing the "Fit" Older Patient for Chemotherapy. Oncology, 28, 594, 596, 598-599.

[39] Lichtman, S.M. and Villani, G. (2000) Chemotherapy in the Elderly: Pharmacologic Considerations. Cancer Control, 7, 548-556.

https://doi.org/10.1177/107327480000700606

[40] Mohile, S.G., Mohamed, M.R., Culakova, E., Xu, H., Loh, K.P., Magnuson, A., Flannery, M.A., et al. (2020) A Geriatric Assessment (GA) Intervention to Reduce Treatment Toxicity in Older Patients with Advanced Cancer: A University of Rochester Cancer Center NCI Community Oncology Research Program Cluster 
Randomized Clinical Trial (CRCT). Journal of Clinical Oncology, 38.

https://doi.org/10.1200/JCO.2020.38.15 suppl.12009

[41] Li, D., Sun, C.-L., Kim, H., Chung, V., Koczywas, M., Fakih, M., Chao, J., et al. (2020) Geriatric Assessment-Driven Intervention (GAIN) on Chemotherapy Toxicity in Older Adults with Cancer: A Randomized Controlled Trial. Journal of Clinical Oncology, 38. https://doi.org/10.1200/JCO.2020.38.15 suppl.12010

[42] Soo, W.-K., King, M., Pope, A., Parente, P., Darzins, P. and Davis, I.D. (2020) Integrated Geriatric Assessment and Treatment (INTEGERATE) in Older People with Cancer Planned for Systemic Anticancer Therapy. Journal of Clinical Oncology, 38. https://doi.org/10.1200/JCO.2020.38.15 suppl.12011 